\title{
Exploring Brown and Levinson's Politeness Strategies: An Explanation on the Nature of the Politeness Phenomenon
}

\author{
Putri Adrian Sapitri ${ }^{1}$, Aprilia Chasanah ${ }^{2}$, Avivah Adinda Putri ${ }^{3}$ and Jessica Paulima ${ }^{4}$ \\ ${ }^{1}$ SMK Negeri 5 Pekanbaru, Indonesia \\ ${ }^{2}$ SMK Migas Teknologi Riau, Pekanbaru, Indonesia \\ ${ }^{3,4}$ SMA Negeri 3 Pekanbaru, Indonesia \\ putriadriansapitri14@gmail.com
}

\section{ARTICLE HISTORY \\ Received : 2019-12-02 \\ Revised : 2019-12-03 \\ Accepted : 2019-12-20}

\section{KEYWORDS}

Politeness

Politeness Strategy

Face

FTA

\begin{abstract}
This study aimed at reviewing and see Brown and Levinson Politeness strategies proposed in their book (1978) entitled "POLITENESS: Some Universals in Language Usage" still can be used in the present situation. Brown and Levinson (1978) developed a theory to explain phenomena related to the Politeness on verbal communication and non-verbal. This article using a content analysis approach as a qualitative. This article is interested in focusing on the types of politeness strategies put forward by Brown and Levinson (1978). This study sees over the past three decades; there has been a significant increase in research on politeness strategies from social and linguistic aspects showing from the many papers still found using BL framework of politeness strategies. This present study also sees politeness strategies proposed by Brown and Levinson still can be used in a current situation related to politeness and extended onto many discourse contexts, both verbal and non-verbal communication.
\end{abstract}

\section{Introduction}

The theory of Brown and Levinson in Politeness extensively uses as basic research by researchers in the field of not only in linguistics but also in Economic, Psychology, and so on. In the last three decades, the research on politeness strategies has increased significantly in terms of social and linguistic aspects. It is evident which comes from the various papers appear on the issues in the international journals and monographs. The politeness strategy proposed by Brown and Levinson (1987) for oral discourse can be applied to interpret the scientific culture of scientific writing. Brown and Levinson developed a theory to explain phenomena related to the politeness on verbal communication and nonverbal communication.

In general, people usually behave in everyday interactions because they care about their public selfimage. According to Brown and Levinson (1987), the act of maintaining a face in pragmatic courtesy includes actions that threaten faces and actions to save faces. Following the theory of politeness, a face consists of two related elements: a positive face and a negative face. A positive face is defined only as a 'self-image' while a negative face is the desire to have freedom. Besides, Leech (1983) has proposed the concept of modesty itself through a set of principles.
Indeed, this is a way to explain how politeness operates in conversation exchange. Brown and Levinson's Politeness Theory also outlines four main types of politeness strategies that include baldness on record, negative politeness, positive politeness, and not being noted. These strategies are used to express messages to save the listener's face when facial actions are desired. In communication, there is twopart. The first of all is verbal communication, and the second is non-verbal communication (Weaver, R., \& Hybells, S. 2007).

Verbal communication can be seen by way perspective of linguistics features, namely length of speech, speed of expression, loudness, etc. For example "Where are you going?" its can expressed differently depending on who the speakers is, to whom them speaks, on what occasion the utterance is expressed and so on (Mujiyanto, Y. 2017). For another example like the word "Be Quiet!" this is a polite word when parents tell their children to be quiet in certain situations. But this word would be impoliteness if the children were telling their parents to be quiet. Verbal communication can also be calculated from a socio-cultural perspective background such as the face, strength, status, age, gender, social distance, kinship, participant role, and discussion in the talk community. 
According to Halliday (2003), "Almost every saying have an ideational meaning, which is related to processes and things from the real world, and an interpersonal meaning, related to the role and attitude adopted and assigned by the speaker" (p. 83). The act of politeness becomes an inseparable part and is limited by socio-culture where the settings are applied. For example, level of courtesy greetings can be expressed as sayings like "Good morning", "Good afternoon", "Hi", and "Hello", whereas like Indonesian, questions like "Where are you going?" answer with expressions like "There". In other words, cultural differences tend to bring up different ways of expressing the act of politeness. Speech rated being polite in a cultural setting can be considered rude in other settings.

As a result, it is necessary to cross-cultural interlocutors to realize the differences that exist in realizing speech degree of politeness according to linguistics and socio-cultural aspects that are used as politeness action parameters. The result that is always needed to reconstruct speech in language while maintaining a degree of politeness contained in general, accurate, and acceptable language, be it original, translation, or rendering back - success in maintaining a degree of politeness of interpersonal speech in a language and restructure them in other languages. The language implies dynamic or achievement functional equality between the two languages. Maintenance of politeness Interpersonal speech requires maintenance socio-cultural aspects involved in production sayings in various languages.

The phenomenon, culture is a homogeneous internal, even though it is different. As a result, the scholars came out with claims that the faces and the principle of politeness were general (Terkourafi, 1005). In response to these arguments, the second group of scholars concentrated on the definition and existence of decency norms in all cultural differences. They believe in variations of politeness across cultures or in culture. In view of this heterogeneity, the universal nature of the concept of modesty may not be acceptable for all cultures, and the role of the recipient in evaluating politeness is also essential and significant, contrasting with the theories put forward by the first group.

Furthermore, politeness is no longer only refers to the strategy used between the speaker and the listener. It modified to include exchange studies in certain situations (Terkourafi, 1005). Thus, Leech (1005) proposes his new theory namely Grand Strategy of Politeness, in which he modified the previous courtesy theory (1983) to discuss politeness strategies and social factors that can influence their use in every act of communication in cultures other than the West.
The act of politeness becomes an inseparable part and is limited by socio-culture where the settings are applied. For example, level of courtesy greetings can be expressed as sayings like "Good morning", "Good afternoon", "Hi", and "Hello", whereas like Indonesian, questions like "Where are you going?" answer with expressions like "There". In other words, cultural differences tend to bring up different ways of expressing the act of politeness. Speech rated being polite in a cultural setting can be considered rude in other settings. As a result, it is necessary to crosscultural interlocutors to realize the differences that exist in realizing speech degree of politeness according to linguistics and socio-cultural aspects that are used as politeness action parameters. The result that is always needed to reconstruct speech in language while maintaining a degree of politeness contained in general, accurate, and acceptable language, be it original, translation, or rendering back - success in maintaining a degree of politeness of interpersonal speech in a language and restructure them in other languages. The language implies dynamic or achievement functional equality between the two languages. Maintenance of politeness Interpersonal speech requires maintenance sociocultural aspects involved in production sayings in various languages.

The hints of politeness in the non-verbal form have used Verbal theory politeness, where instructions are interpreted through coding techniques in interpretive techniques applied in verbal politeness theory reviews. The term intangible is used here to emphasize facts that politeness is a variant of meaning. Thus, it concerns what is behind the form perceived by our visual senses. After the instructions are interpreted, actions for decency are presented, taken from real-life daily practices. Silence, gestures, gifts, observance of norms, rules and regulation are part of the form of non-verbal communication. The purpose of this paper is to want the reader to know why politeness is an essential thing in life relations in verbal and non-verbal communication are needed. Therefore, This paper focuses on exploring politeness strategies put forward by Brown and Levinson (1978) related to verbal and non-verbal communication. The purpose of this paper to give information that each interlocutor must maintain the speaker's self-esteem. This strategy must be used in verbal and non-verbal communication.

\section{Method}

This study uses a qualitative approach to find out the modesty strategies proposed by Brown \& Levinson. Therefore, this review-based research tries to illustrate how the strategies that have been developed by Brown \& Levinson. This research also looks at the strengths and weaknesses of the theory. This study also tries to see whether the theory still been used by current studies. This research hopes to 
be able to provide a simple picture while recommending the findings or steps in the article, whether it is feasible to be replicated or not in the same study.

\section{Strength and Weaknesses}

The concept of politeness in this study is primarily based on the politeness theory by Brown and Levinson (1978, 1987), which incorporates three basic notions: face, face-threat (FTA) actions and politeness strategies.

Brown and Levinson's 'politeness' theory was initially published in 1978. This is a theory that has caused quite a lot of controversy; although widely recognized in the literature, it also attracts a lot of criticism (e.g. Matsumoto, 1988; Ide, 1989). The phenomenon of 'politeness' can be identified by using Brown and Levinson's theory is not only in goaloriented interactions but also in interactions that are not goal-oriented (Kitamura: 1000). Brown and Levinson's work consists of two parts. The first part is their fundamental theory of the nature of 'politeness' and how it functions in interactions. The second part is a list of 'politeness' strategies with examples from three languages: English, Tzeltal, and Tamil. In the theoretical part of their work, Brown and Levinson introduced the 'face' idea to describe 'politeness' in the broadest sense.

In other words, everyone who interacts has an interest in maintaining two types of 'face' during interaction: 'positive face' and 'negative face'. Brown and Levinson define 'positive faces' as positive and consistent images that people have about themselves, and their desire for approval. On the other hand, negative faces 'are" necessary claims to territory, personal protection, and the right not to be disturbed "(p. 61). Utilizing the idea of 'face', 'politeness' is considered to have a dual nature: 'positive politeness' and 'negative politeness'. 'Positive politeness' is expressed by satisfying 'positive faces' in two ways: 1) by showing similarities among the participants; or 1) by expressing appreciation for the other person's self-image. 'Negative politeness' can also be expressed in two ways: 1) by saving 'interlocutors' (either 'negative' or 'positive') by reducing threatening facial actions (from now on referred to as FTA), such as giving advice and disagreeing; or 1) by satisfying negative faces 'by showing respect for the recipient's rights that are not imposed. According to Schegloff and Sacks, 1973; Scollon and Scollon, 1981; Usami, 1998 "Although the theoretical part of this work seems to have the potential to be applied to various types of interactions, Brown and Levinson's list of 'politeness' strategies mainly includes certain types of interactions that are very limited. The examples they provide mainly consist of single sayings that have or presuppose clear communicative goals, such as asking to borrow a book or giving advice.
Brown and Levinson tend to ignore the fact that most single utterances are only constituents of a greater exchange between two or more people who interact. First, they do not pay attention to phenomena that occur throughout the discourse, such as the return channel or the overall sequence of speech (cf. Schegloff and Sacks, 1973; Scollon and Scollon, 1981; Usami, 1998). Second, they ignore any interactions, such as simply enjoying a relaxed conversation, which does not involve predetermined goals. The theory of politeness suggested by Brown and Levinson is the most influential work in the field of interlanguage science, which is widely used (1978, 1987) (Brunet, Cowie, Donnan, \& Douglas-Cowie, 1011 , p. 1). The theory concentrates primarily on how politeness is conveyed to protect the identity of the speaker. Brown and Levinson (1987) based on their Goffman theory $(1955,1967)$, which introduced a positive face first and demonstrated importance and necessity in specific social interactions (Brunet et al., 1011, p. 1).

'Positive politeness' refers to what can be conveyed to satisfy the needs of the positive face of a person, whereas 'negative politeness' works in two ways. First, to save the "interlocutor of the face", it can be expressed negatively and positively. Second, by respecting the needs of the negative face, it can also be expressed by showing respect for the recipient, remembering that their rights must be respected and 'not imposed' (Kitamura, 1000, p. 1). At this point, they cooperate in any social communication for the interlocutor to defend their faces, because they need to defend everyone's faces depends on others (Wijayanto, Laila, Prasetyarini, \& Susiati, 1013). Therefore, Brown and Levinson (1987) proposed their politeness technique to shield the interlocutor's face in any social interaction as they communicate their speech behaviour.

They believe that this strategy may be universal in allowing the speaker to understand the social factors in which the speaker defends others' faces by using his speech actions. When clarifying modesty strategies, the significance of social factors has prompted researchers to justify it before describing modesty strategies. Brown and Levinson (1987) reflect on three social factors that the speaker will consider while communicating with each other. There are 1) Power, 2) Social distance and 3) Level of coercion. Power refers to both the speaker and the listener's social status. Social distance is defined as a factor indicating the degree of mutual contact between the other parties. (Brown Levinson, 1987). Kida (1011, p. 183) said that "reverence, respect and politeness" can be conveyed by the use of different linguistic forms.

Brown and Levinson (1987) state that politeness strategies are developed to save the "face" of the listener. The face refers to the respect a person has for 
himself, and maintain "self-esteem" in public or personal situations. In this case, the speaker is usually trying to avoid other people being embarrassed or making him feel uncomfortable.

Politeness can be done distance or closeness socially. In formal conditions, the speaker must speak more politely to show respect to listeners. Being polite depends on how the speaker uses words or clauses to convey ideas to the listener when someone interacts with other people its divided being 2 part. Its verbal and non-verbal communication.

In verbal communication If the language procedures someone does not comply with social and cultural norms, he will get value negative, for example, said people who are not polite, arrogant, arrogant, selfish, no civilized, even uncultured (Muslich, 2006: 2). Verbal behaviour is a crucial function, for example, is seen in how speakers express a command, must, or prohibition to do something to the speech partner, while nonverbal behaviour appears from physical gestures accompanying it. The successful use of politeness strategies in language creates communication effectively.

For example, the politeness strategy analyzed focuses on the speaker in interactional opportunities that become available through dialogue. This focus choice increases the likelihood of analysis becoming more at the participant level, that is, it shows the speaker and listener anticipate the interpretation combined with the status received from the speaker (Markus. M., 2011). Another exciting area of research that can be explored will involve the comparison of online seminars with those that take place face to face, to see if and in what ways politeness strategies differ. The result is evidence of the politeness strategies used by participants in online interactions that are expected to be found in face-to-face conversations. The use of politeness strategies by teachers can be intentional because teachers, in this position of authority, may be aware of the impact of selected/structured features / structured linguistic speech on students and meaning in conversation. Usually, a student may not pay attention to the use of hedges, formula expressions, special speech acts and teacher allowances for the turn-taking process to occur, but this is perhaps the most essential premise where linguistic expressions are classified as politeness strategies and used in interactions, breaks (Markus. M., 2011).

Nevertheless, Myers, in his study "Politeness in the scientific text" (1989) was linked to what Brown and Levinson proposed in their book "Politeness: Some universals in language usage" (1978). Myers (1989) pioneers the implementation of the politeness methods of Brown and Levinson (1987) in written papers and explores the presence of politeness in scientific articles. While one of the best-known books on persuasion techniques used by Mullholland (1994) to reinforce insight beyond the tactics employed in the economic text by journalists. She was the first person to start compiling effective persuasion strategies in communication. In her book, Mulholland (1994) provides a list of the collection of the 300 most powerful persuasive techniques used in speech or communication writing.

Additionally, she was focused on studying the tactics and their strong values beyond the tactics used in daily lives (Hamuddin, 2012). Politeness theory has various shortcomings and problems that reduce their efficiency in success interactive communication analysis. Universalism, for example, is not well defined by Brown and Levinson's' theories. Also, the model is not transparent, whether to include certain cultures as well as aspects of cross-cultural communication. Besides, facial theory generally implies the problem of how to correct defining ideas about faces and is a matter of how to limit the threat effects of some speech actions and functions. This theory has the same shortcomings as those found in the 'Cooperative Principles' communication approach.

Brown and Levinson (1978:68) explained that actions could damage or threaten people's faces, and they are known as face-threatening (FTA) actions. FTA can affect the positive or negative face of the listener or even the positive or negative face of the speaker. The speaker should pursue other techniques to reduce the likelihood of harm to the audience or the speaker's face. Such tactics are known as "strategies of politeness" The idea of politeness technique has been created to avoid embarrassing others or making it awkward to save the audiences' "names" in both verbal and non-verbal communication.

Eventually, intending to counteract the unwanted effects of FTAs, people have developed a politeness strategy which is an easy way to remedy or mitigate the risk of hearing. With evidence from three different languages, namely English, Tzeltal, and Tamil, Brown and Levinson's theory of politeness (1978) support their findings on politeness and, most importantly, on the universality of face concepts. The following sub-sections deal, on the one hand, with the concept of politeness and universalism and, on the other hand, various critiques or modifications of one of the model elements; primarily the concepts of face, face-threatening act and the factors which affect the production and interpretation of politeness. Brown and Levinson said that in social interaction, they originated the notion of the Goffman (1963) image.

"Our notion of 'face' is derived from that of Goffman and from the English folk term, which ties up face notions of being embarrassed or humiliated, or 'losing face'. Thus, face is something that is emotionally invested, and that can be lost, maintained or enhanced, and must be continuously attended to in interaction. 
In general, people cooperate (and assume each other's cooperation) in maintaining face in interaction, such cooperation is based on the mutual vulnerability of face". Brown and Levinson (1987:63). Goffman published the article 'On Face Work' in 1963, in which he first made the term 'face'. "Face is a mask that changes depending on the viewer and social interaction," he says. He addresses face concerning how people present themselves and explains that our social interactions influence our entire identity. The face is divided into two groups by Goffman (1963), namely positive face and negative face. He describes a positive face as the urge to be seen as the right person and a negative one as an autonomous desire. He also states that the mask is maintained by the listener, not the speaker.

In communicative cases, the term is universal but is used in specific cultures. It is characterized psychologically, philosophically and symbolically as "the positive social value that an individual effectively claims for himself following the line that others have adopted during a particular contact." Face generally involves mutual recognition of the interlocutors as social members of society. The face can be lost, preserved or strengthened and communicate continuously (Goffman, 1963).In politeness theory, the concept of face has come to play an important role. Therefore, Brown and Levinson (1978) have chosen it as the central notion for their study of universals in language usage and politeness phenomena, based on earlier work on the face by Goffman (1963). In their research, Brown and Levinson (1978) described the idea of the face as "the public self-image that each individual wants to claim for themselves" and clarified the face as something emotionally engaging and that the face can be lost. It preserved or strengthened and that the relationship needs to be continuously attended to and accepted in some respects. Brown and Levinson (1978 and 1987) have been saying, in their study of politeness, that we are all driven by two wishes: positive face and negative face. The analysis, therefore, considers that the negative aspect relates to autonomy: freedom from coercion and fundamental claim to territories, personal protection, and the right to non-distraction, i.e. freedom of action and free imposition.

\subsection{Face}

The politeness theory of Brown and Levinson (1978) has become a paradigm for study on politeness strategy. The central point of Brown's and Levinson's theory is the idea of the face, as suggested by Goffman (1967) who described the face as:

"The positive social interest of an individual essentially claims for himself the line taken by others during a particular touch." The face is an image of oneself with accepted social attributes-albeit an image that others can share as if a person shows his occupation or religion with good shows for himself." (Goffman 1967:5).

\subsection{FTA}

According to Brown and Levinson (1987, 1978), acts of facial threats may threaten the face of the speaker or the face of the audience, threatening the face, either positive or negative. FTA or Face Threatening Act involves showing expressions of thanks, condolences, promises, and non-verbal behaviours such as stumbling, falling or utterances threatening each other's intrinsic face (positive or negative). It also includes disagreement critique, requests, lousy news and demand. For example, simple demands threaten the negative face of the target because compliance with the request interferes with its will to remain independent. Besides, FTA is an act that threatens an interlocutor's face. Brown and Levinson (1987:65) proposed that when facing the need for FTA, a person should either explicitly and effectively execute FTA, or attempt to mitigate the effect of FTA on the positive and negative face of the listener.

\subsection{Politeness Strategies}

The concepts of politeness strategies are developed to prevent someone from being embarrassed or from feeling uncomfortable, to save the listener's "face". The politeness strategies of Brown and Levinson (1978) could be divided into four main strategies: bald-on-record, positive politeness, negative politeness and off-record politeness strategies. Throughout his research, Hamuddin (2012) thought that these four techniques could still be used in the current situation.

\subsubsection{Bald-on-record}

According to Brown and Levinson (1978:74), bald on record strategy is a direct way of saying things, without any minimization to the imposition, in a direct, clear, unambiguous and concise way. There are different kinds of bald-on-record usage in different circumstances. It is because the speaker can have different motives for their wants to do the FTA with minimum efficiency. The motives fall into two classes; one is where the face threat is not minimised and therefore ignored or irrelevant, and the other is where in doing the FTA bald on record, the speaker minimises face threats by implication. Brown and Levinson (1977:100) provide the example of a baldon-record strategy and suggest that the use of bald-onrecord direct imperatives is evident. Imperatives are often smoothed with hedges or traditional signs of politeness.

\subsubsection{Positive politeness}

The second strategy is constructive politeness and is usually found in groups of friends or in situations where people of certain social circumstances are 
reasonably familiar to each other. It typically tries to minimize the difference between them by demonstrating friendliness and a keen interest in wanting to follow the address (minimize FTA), i.e. this technique aims to minimize the danger to the audience.

Positive politeness is less polite than negative politeness because the particular face violated by the FTA is not necessarily corrected. Brown and Levinson (1978:106) note that good politeness is that the correction partly meets the desire that one desires, or that in some ways some of the redresses are close to the desire of the addressee. Brown and Levinson (1978), added that the dimension of insincerity in inflated expressions of consent or interest compensates by implicating that the speaker genuinely wants a right image to be improved, for example.

\subsubsection{Negative Politeness}

Brown and Levinson (1978:129) said: "It is a remedial action directed at the negative face of the addressee, who needs unimpeded freedom of action and consideration from the addresser and differentiates between the negative and positive politeness. The negative politeness is the core of the respective compartment, just as the heart of ' families' and 'joking' is positive politeness. In addition, Brown and Levinson (1978:130) say that the negative politeness outputs in all forms are used in general for social "distancing". Therefore, they are likely to be used whenever a speaker or a sender wants to put a social brake on the course of interaction.

\subsubsection{Off-record}

Brown and Levinson (1978:216) noted that for offrecord strategy "the actor leaves it up to the addressee to decide how to interpret the act". The off-record strategy as a communicative act which is done in such a way that a clear communicative intention cannot be attributed. In this situation, the actor leaves himself "out" by giving some defensible interpretations. In addition, Brown and Levinson (1978:230-232) listed one of the main strategies of non-recording and its sub-categories, giving hints, giving association clues, presupposing, understating, overstating, using tautologies, using contradictions, being ironic, using metaphors, and using a rhetorical question. The other primary technique is unclear or uncertain, and its subcategories are ambiguous, vague, overgeneralizing, hearing-displacing and incomplete.

\section{Conclusion}

This research provided an overview of Brown and Levinson's politeness theory (1987) discussing any flaws or strengths of this theory. It was also designed to debate the universality of politeness theory for all cultures with or against it. Firstly, this lack of universality and the extension by Brown and
Levinson's (1987) principle of courtesy to all cultures. It is clear from the many critiques aimed at Brown and Levinson (1987) because of their claims to be universal in their ideas and their west-oriented biases and listeners, and focus on "Western individual orientation." Secondly, this paper also shows that this paper suggests that the definition extends to all communicative politeness in East and West languages and can explain it. As described above, in most, if not all, languages and cultures, the theory seems reasonable and efficient. It encompasses most of the common variants that influence policy choice and has different aspects that are acceptable for most kinds of debate and circumstances. Therefore, directed at the speaker and audience.

Previous studies have shown that politeness strategies can not only be applied in oral communication but also written communication. Many of these studies are based on Brown and Levinson's $(1978,1987)$ theory to determine the nature of politeness phenomena in written communication. A theory was developed by Brown and Levinson (1978) to explain the nature of the phenomenon of politeness depending on spoken discourse. The central concept of the theory is an arrangement of politeness along a line from the least polite to the most polite.

\section{References}

Brown, P., Levinson, S. C., \& Levinson, S. C. (1987). Politeness: Some universals in language usage (Vol. 4). Cambridge university

Brunet, P. M., Cowie, R., Donnan, H., \& DouglasCowie,

E.

(2012). Politeness and social signals. Cognitive processing, 13(2), 447-453.

Eelen, G. (2014). A critique of politeness theory (Vol. 1). Routledge.

Fraser, B. (1990). Perspectives on politeness. Journal of pragmatics, 14(2), 219-236.

Geoffrey, L. (1983). Principles of pragmatics. London and New York: Longman.

Geyer, N. (2004). Discourse Politeness in Japanese Conversation: Some Implications for a Universal Theory of Politeness.

Goffman, E. (1978). The presentation of self in everyday life (p. 56). London: Harmondsworth.

Hamuddin, B. (2012). A comparative study of politeness strategies in economic journals (Doctoral dissertation, University of Malaya).

Hamuddin, B., \& Noor, F. N. M. (2015, August). A Closer Look on Politeness Strategies in 
Malaysian Economic Journal. In 2nd International Seminar on Linguistics (p. 52).

Ide, S. (1989). Formal forms and discernment: Two neglected aspects of universals of linguistic politeness. Multilingua-journal of crosscultural and interlanguage communication, 8(2-3), 223-248.

Kida, I. (2011). Language distance across cultures as a way of expressing politeness and not only. In Aspects of Culture in Second Language Acquisition and Foreign Language Learning (pp. 183-191). Springer, Berlin, Heidelberg.

Kitamura, N. (2000). Adapting Brown and Levinson's 'politeness' theory to the analysis of casual conversation. In Proceedings of ALS2k, the 2000 Conference of the Australian Linguistic Society (pp. 1-8).

Lakoff, R. (1973). Language and woman's place. Language in society, 2(1), 45-79.

Lakoff, R. (1973). The logic of politeness; or minding your ps and qs Papers from the 9th Regional Meeting of the Chicago Linguistic Society. Chicago: Chicago Linguistic Society, 292-305.

Mao, L. R. (1994). Beyond politeness theory: 'Face'revisited and renewed. Journal of pragmatics, 21(5), 451-486.

Markus, M. (2011). Politeness in interaction: an analysis of politeness strategies in online learning and teaching.

Martínez-Flor, A. (2008). Analysing request modification devices in films: Implications for pragmatic learning in instructed foreign language contexts. In Intercultural language use and language learning (pp. 245-280). Springer, Dordrecht.

Marwa, M., \& Herdi, H. (2017). Do Native Speakers in Youtube Videos Benefit EFL Students' Phonological Appropriation?. Lectura: Jurnal Pendidikan, 8(2)

Matsumoto, Y. (1989). Politeness and conversational universals-observations from Japanese. Multilingua-Journal of Cross-Cultural and Interlanguage Communication, 8(2-3), 207-222.

Mills, S. (2003). Gender and politeness (Vol. 17). Cambridge University Press.

Mujiyanto, Y. (2017). The verbal politeness of interpersonal utterances resulted from backtranslating indonesian texts into english. Indonesian Journal of Applied Linguistics, 6(2), 288-300.
Reiter, R. M. (2000). Linguistic politeness in Britain and Uruguay: A contrastive study of requests and apologies (Vol. 83). John Benjamins Publishing.

Schegloff, A. E. \& Sacks, H. 1974. Opening Up Closing. Dalam J. Baugh dan Jsherzer (Eds.), Language in Use: Reading in Sociolinguistics (hlm.69-99). Englewood Cliffs, New Jersey: Prentice Hall

Scollon, R., \& Scollon, S. W. (2001). Intercultural Communication A Discourse Approach Second Edition. Language in Society-Oxford-, 21.

Terkourafi, M. (2005). An argument for a framebased approach to politeness. Broadening the horizon of linguistic politeness, 139, 99.

Wang, N., Johnson, W. L., \& Gratch, J. (2010, June). Facial expressions and politeness effect in foreign language training system. In International Conference on Intelligent Tutoring Systems (pp. 165-173). Springer, Berlin, Heidelberg.

Watts, RJ (2003). Kesopanan . Cambridge University Press.

Weaver, R., \& Hybells, S. (2007). Communicating effectively. Boston: McGraw Hill.

Wijayanto, A., Laila, M., Prasetyarini, A., \& Susiati, S. (2013). Politeness in Interlanguage Pragmatics of Complaints by Indonesian Learners of English. English Language Teaching, 6(10), 188-201. 